Article

\title{
Improvement of Transverse-Flux Machine Characteristics by Finding an Optimal Air-Gap Diameter and Coil Cross-Section at the Given Magneto-Motive Force of the PMs
}

\author{
Grebenikov Viktor ${ }^{1}\left(\mathbb{D}\right.$, Oleksandr Dobzhanskyi $^{2, *}$, Gamaliia Rostislav $^{1}\left(\mathbb{D}\right.$ and Rupert Gouws ${ }^{3}$ \\ 1 Institute of Electrodynamics, National Academy of Sciences, Peremohy Ave, 56, 03057 Kyiv, Ukraine; \\ odobz@PointPark.edu (G.V.); rgamaleya@gmail.com (G.R.) \\ 2 Department of Natural Sciences, Engineering and Technology, Point Park University, \\ Pittsburgh, PA 15222, USA \\ 3 School of Electrical, Electronic and Computer Engineering, North-West University, \\ Potchefstroom 2520, South Africa; rupert.gouws@nwu.ac.za \\ * Correspondence: odobzhanskyi@gmail.com; Tel.: +1-541-667-2973
}

Citation: Viktor, G.; Dobzhanskyi,

O.; Rostislav, G.; Gouws, R.

Improvement of Transverse-Flux

Machine Characteristics by Finding an Optimal Air-Gap Diameter and Coil Cross-Section at the Given Magneto-Motive Force of the PMs. Energies 2021, 14, 755. https:// doi.org/10.3390/en14030755

Academic Editor: Anibal De Almeida Received: 28 December 2020

Accepted: 21 January 2021

Published: 1 February 2021

Publisher's Note: MDPI stays neutral with regard to jurisdictional claims in published maps and institutional affiliations.

Copyright: (c) 2021 by the authors. Licensee MDPI, Basel, Switzerland. This article is an open access article distributed under the terms and conditions of the Creative Commons Attribution (CC BY) license (https:// creativecommons.org/licenses/by/ $4.0 /)$.

\begin{abstract}
This paper presents analysis and study of the single-phase transverse-flux machine. The finite element method results of the machine are compared with the laboratory measurements to confirm the accuracy of the computer model. This computer model is then used to investigate the effect of the machine's geometry on its output characteristics. Parametric analysis of the machine is carried out to find the optimal air-gap diameter at which the cogging torque of the machine is minimal. In addition, the influence of the coil cross-section on the torque and output power characteristics of the machine is investigated and discussed.
\end{abstract}

Keywords: generator; permanent magnet; torque density; transverse-flux machine

\section{Introduction}

Motors with a transverse magnetic flux (transversal flux machines-TFMs) have a high potential in terms high torque and power density [1-17]. In addition, TFMs allow implementing a multi-pole design (30-60 poles), which makes it possible to create lowspeed high-torque machines for direct (gearless) applications. TFMs can be designed with a simple cylindrical O-shaped stator winding [15]. In order to develop a multi-phase TFM, identical single-phase units can be stacked together and shifted by the corresponding phase angle. Despite these advantages, only a few companies are adopting TFM production recently. Complex design, high cogging torque, and high manufacturing cost prevent many industries from adopting these machines. However, in recent decades, due to the development of simulation-based software, various numerical methods, and modern manufacturing technologies, TFMs have gotten more interest from both academia and industry. Currently, several research groups are actively involved in the design and production of this type of machine [1,2] including Rolls Royse [6].

When developing and designing a TFM machine, a number of important factors should be considered. Among these factors are minimization of the cogging torque, optimization of the winding and finding an optimal configuration of the machine with the best specific characteristics. With a wrongly chosen cross-section, TFM performance can be degraded. Because there is a lack of precise knowledge of how the winding height influences the dynamic characteristics of the TFM machines, this study aims to address this issue in more detail. Therefore, the purpose of this work is to study the influence of the winding height of the characteristics of the transverse-flux machine.

The goal of the presented paper is to design a cost-effective, high-torque density single-phase TFM. To decrease its manufacturing cost, the discussed machine will not 
oversee magnetic shunts [15], sophisticated shapes of the stator poles, nor complex shapes of the permanent magnets (PMs).

The 3D FEM computer model of the single-phase TFM is parametrically analyzed in this study. To justify the accuracy of the analysis, the results are compared to those of the physical prototype. After the results of the model and prototype matched, the model is then used for further parametric studies. In these parametric studies, the influence of the model's geometry on the output characteristics of the machine are studied, and, thus, the optimal configuration of the machine is determined. The magnetostatic, parametric and dynamic characteristics of the discussed machines are calculated using Simcenter MagNet and Ansys Maxwell.

The paper is organized as follows. In Section 2, numerical and experimental studies of the single-phase TFM with an inner rotor are carried out and compared in Section 3. The discussion of the results is provided in Section 4. And finally, the conclusions are given in Section 5 .

\section{Computer and Experimental Investigation of the Single-Phase TFM with an Inner Rotor}

The TFM with an internal rotor and its basic dimensions in $\mathrm{mm}$ are shown in Figure 1. The machine consists of the $15 \mathrm{U}$-shaped stator poles distributed circumferentially around the machine's rotor. The single-phase O-shaped coil is placed inside of the stator poles. The rotor has $60 \mathrm{PMs}$ arranged in two rows and are firmly attached to the back-iron cylinder. The key parameters of the machine along with winding data are enclosed in Table 1.
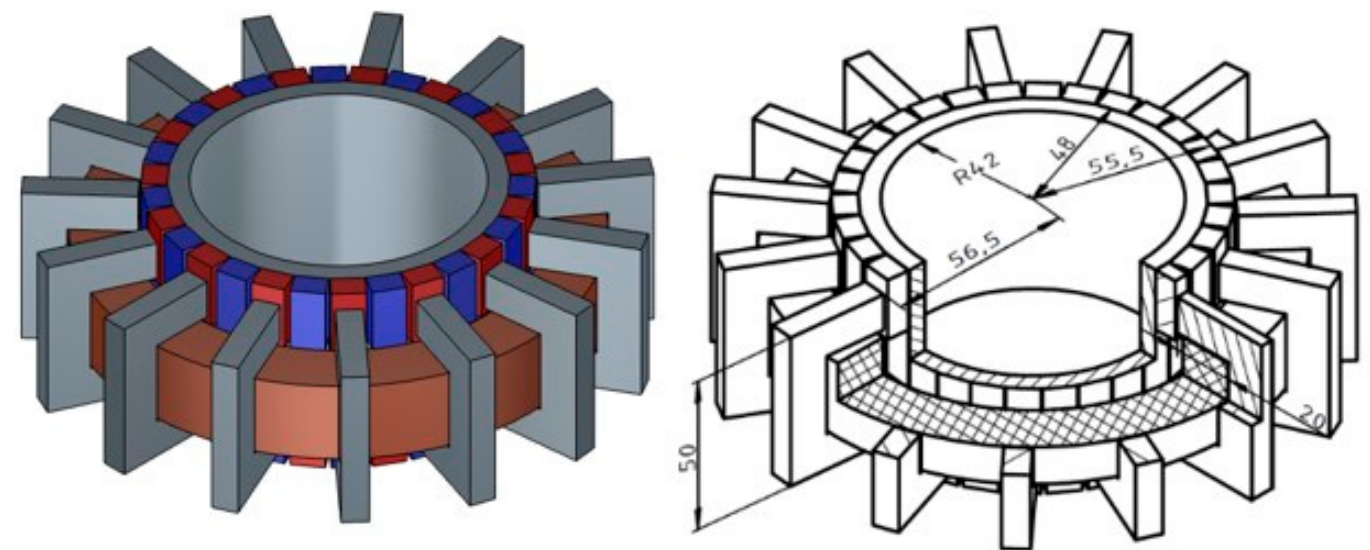

Figure 1. The initial configuration of the single-phase transversal flux machines (TFM) with an inner rotor.

Table 1. Key parameters of the single-phase TFM with an inner rotor.

\begin{tabular}{cc}
\hline Parameter & Value \\
\hline Number of stator poles, $N$ & 15 \\
Number of rotor poles, $p$ & 30 \\
Outer rotor diameter, $\mathrm{mm}$ & 111 \\
Inner rotor diameter, $\mathrm{mm}$ & 82 \\
Inner stator diameter, $\mathrm{mm}$ & 113 \\
Air gap, mm & 0.8 \\
Residual flux density of the PMs & $0.78 \mathrm{~T}$ \\
Permeability of the PMs, $\mu_{\mathrm{r}}$ & 1.1 \\
PMs size, mm & $20 \times 10 \times 7.5$ \\
Number of PMs & 60 \\
Outer coil diameter, mm & 152 \\
Inner coil diameter, mm & 118 \\
Width of the coil, mm & 26 \\
Number of turns of the coil & 220 \\
\hline
\end{tabular}


Table 1. Cont.

\begin{tabular}{cc}
\hline Parameter & Value \\
\hline Diameter of the conductor, $\mathrm{mm}$ & 1.13 \\
Cross-section of the conductor, $\mathrm{mm}^{2}$ & 1 \\
Resistance of the coil, Ohms & 1.8 \\
\hline
\end{tabular}

To decrease the simulation time of the computer model, a $1 / 15$ of the actual machine's size segment is analyzed instead of the whole model. The 3D FEM model of this segment is shown in Figure 2a. The magnetic flux density distribution in the segment at no load is demonstrated in Figure 2b. The segmented model was validated by comparing its results to the 3D FEM model of the complete model. The analysis shows that the discrepancy between cogging torque, electromagnetic torque, and output power of these models do not exceed $1 \%$.

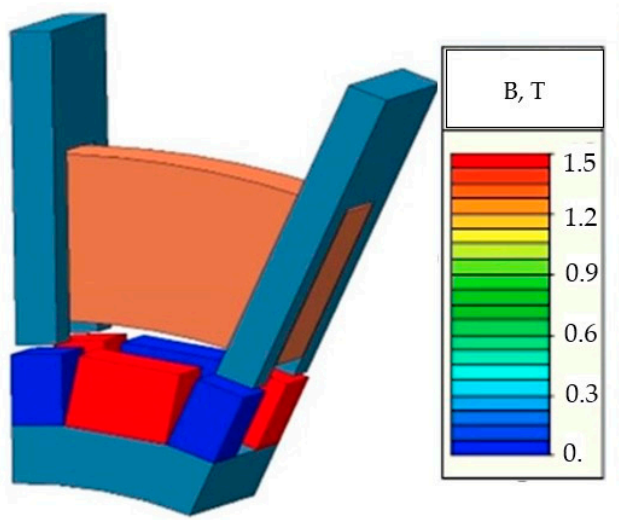

(a)

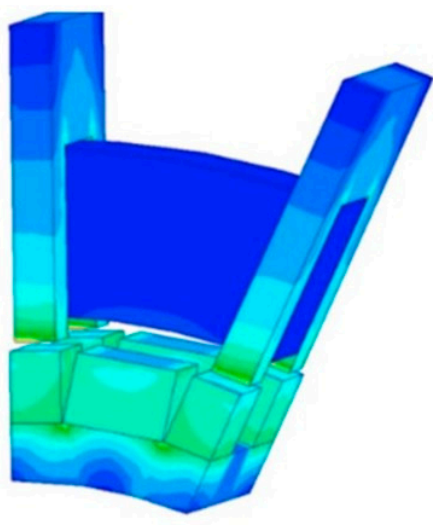

(b)

Figure 2. Computer model of the TFM segment: (a) 3D FEM model of the segment and (b) magnetic flux density distribution in the segment.

To further validate the accuracy of the segmented model of the TFM with an inner rotor, the physical prototype of the machine is built and analyzed experimentally in the laboratory. For this experimental analysis, the prototype was equipped with a measurement system. The measurement system included a digital torque meter and rotor position sensor. The frontal and top views of the prototype model of the TFM with an inner rotor and the measurement system are shown in Figure 3a,b.

A general view of the single-phase prototype of the TFM with measuring sensors is shown in Figure 4. To find the dependence of the electromagnetic torque on rotor 1 angle, the module was equipped with a torque sensor 2 and controller 3 . This output of the torque is then displaced on the controllers screen. Changing the position of the rotor is carried out with the help of two regulating screws 4 . The screw thread stroke is equal to one $\mathrm{mm}$, i.e., when the screw head is turned by one revolution $\left(360^{\circ}\right)$, the rotor turns around its axis by $0.634^{\circ}$. The measurement of the rotor angle is carried out using the angle sensor 5 . The angle sensor is attached to the rotor by a holding magnet, and displace the absolute value of the angle in degrees. 


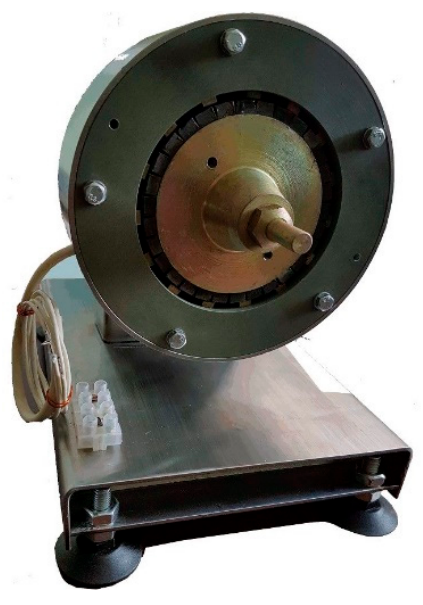

(a)

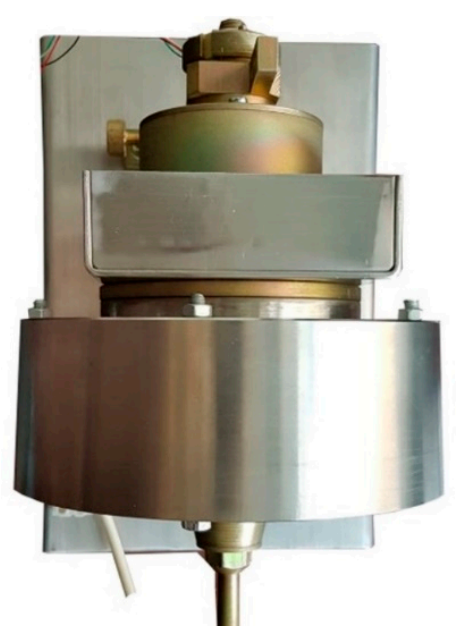

(b)

Figure 3. The frontal and top views of the TFM prototype with an inner rotor: (a) the photograph of the frontal view; (b) the photograph of the top view.

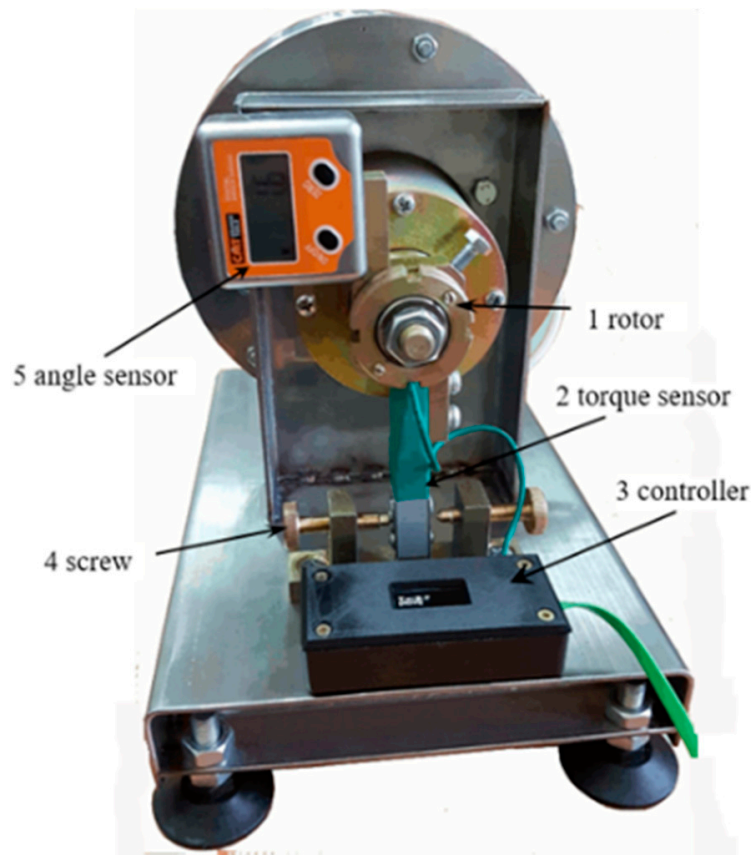

Figure 4. General view of the single-phase prototype of the machine with a measurement system.

The dependence of the cogging torque (no-load condition) and the electromagnetic torque (load condition) on the angle of rotation was determined as follows: by turning the screws 4 clockwise, the rotor is "squeezed out" from the stable position of equilibrium. Moving the screw by half a turn $\left(180^{\circ}\right)$ corresponds to a rotor rotation of $0.317^{\circ}$. Thus, the rotor moves from a position of stable magnetic equilibrium to a position of unstable magnetic equilibrium. The characteristics of the rotor, stator and PMs of the prototype correspond to those of the 3D FEM model: the magnetic core of the rotor is made of steel 1008 (considering nonlinearity of the magnetization curve of steel); stator made of laminated steel 1008 with stacking factor 0.95; and the chosen PM type is N 25, and the residual induction $-\mathrm{B}_{\mathrm{r}}=0.78 \mathrm{~T}$.

A series of laboratory tests were carried out with the prototype to determine the cogging torque, electromagnetic torque, and induced voltage characteristics of the machine. 
Dependence of the electromagnetic torque on the rotor angle was determined for the following values of the current density in the winding: $J=0 \mathrm{~A} / \mathrm{mm}^{2}$ (cogging); $J=1,2,3$, $4,5,6 \mathrm{~A} / \mathrm{mm}^{2}$. As a result of comparison, it was determined that for the current density $J=0-2 \mathrm{~A} / \mathrm{mm}^{2}$ the average deviation between the calculated and experimental data does not exceed $6 \%$, for the current density $J=3-6 \mathrm{~A} / \mathrm{mm}^{2}$ the average deviation does not exceed $10 \%$. Figure $5 \mathrm{a}-\mathrm{c}$ shows the results of comparing the calculated and experimental torque values for the current densities $J=0 \mathrm{~A} / \mathrm{mm}^{2}, J=3 \mathrm{~A} / \mathrm{mm}^{2}$ and $J=6 \mathrm{~A} / \mathrm{mm}^{2}$. Experimental studies were also carried out with a single-phase prototype in the generator mode at no load. In these studies, the generator winding was connected to a rectifier diode bridge. The rotor speed sensor was connected to one of the shaft ends, and a driving motor at the other end. In the course of experiments, the rotation frequency of the shaft was changed using the driving motor. At this time, the generated voltage at the diode bridge terminals was recorded. The results of comparing the calculated and experimental values in the generator mode are shown in Figure 5d. The average deviation between the experimental and calculated values of induced voltage on the rotor speed does not exceed $5 \%$.

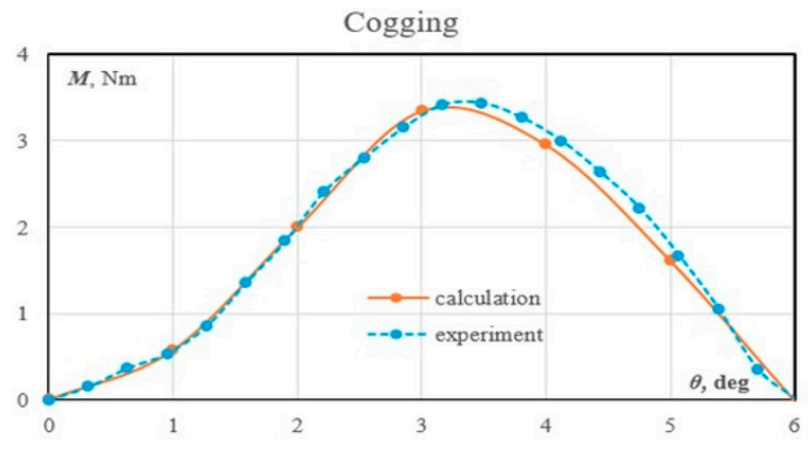

(a)

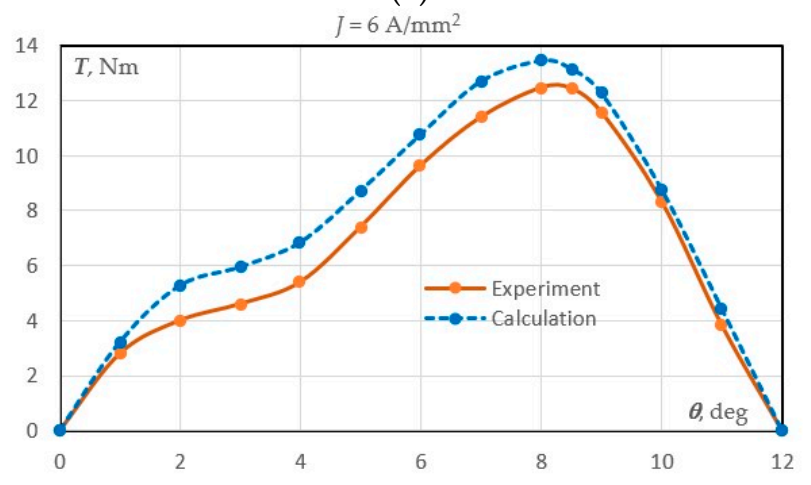

(c)

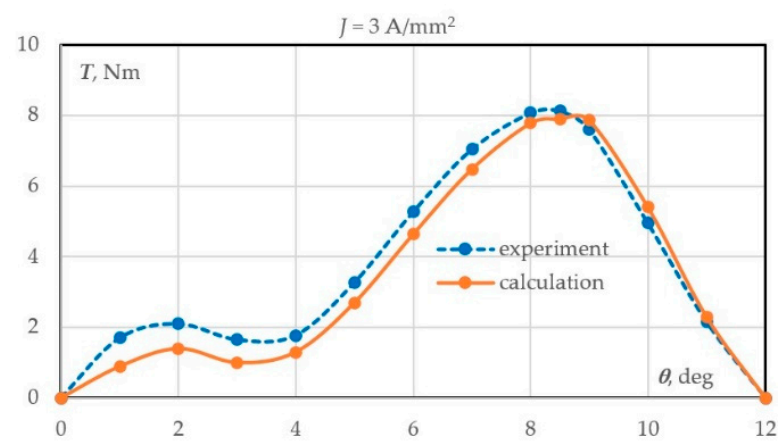

(b)

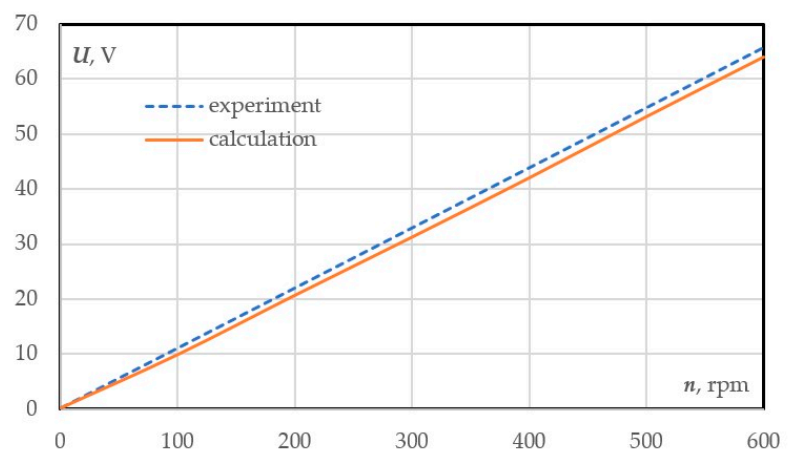

(d)

Figure 5. Electromechanical characteristics of the single-phase TFM with an inner rotor obtained during computer simulation and experimental measurements: (a) cogging torque vs. rotor mechanical angle $\left(J=0 \frac{A}{\mathrm{~mm}^{2}}\right)$; (b) electromagnetic torque vs. rotor mechanical angle $\left(J=3 \frac{A}{\mathrm{~mm}^{2}}\right)$; (c) electromagnetic torque vs. rotor mechanical angle $\left(J=6 \frac{A}{\mathrm{~mm}^{2}}\right)$; and (d) no-load voltage at speed of $600 \mathrm{rpm}$.

Comparison of the computer and experimental results shows that the computer model adequately reflects the physical processes in the studied 3D FEM model. The torque characteristics compared in Figure 5a,b, show that the average discrepancy between the calculated and experimental values of the electromagnetic torque does not exceed $12 \%$. In the range $\theta=0-4$, the mechanical degrees for $J=3 \frac{A}{\mathrm{~mm}^{2}}$ and $J=6 \frac{A}{\mathrm{~mm}^{2}}$ has a discrepancy is higher. The induced voltage characteristics taken in the generating mode show the average discrepancy less than 5\%. Therefore, the 3D FEM model of the TFM can be used further for accurate parametric investigations. 


\section{Parametric Investigation of the Single-Phase and Three-Phase TFM}

\subsection{Varying Air-Gap Radius for Cogging Torque Reduction}

Experimental data obtained on the physical model of the single-phase TFM with an inner rotor, and the calculated data obtained on the basis of computer simulation showed that the studied TFM has a significant cogging torque (Figure 5a). Such cogging torque significantly worsens the characteristics of the machine both in generator and motor regimes and leads to the operational noise, vibrations and high torque pulsations. To reduce the cogging torque, various methods are widely used: skewing the stator or rotor poles for a given angle, placement of the ferromagnetic inserts between the poles with low magnetic permeability, placing an additional stator pole in the stator, etc. These methods usually increase the cost of the machine $[4,11]$.

In this section, a TFM machine with an external rotor is investigated and shown in Figure 6 . In addition to its better cogging torque characteristics previously researched by the authors [15,17], the external rotor structure of this machine has better power to volume capabilities if compared to the inner rotor machine. This is because in the external rotor structure, the empty space inside of the machine is well utilized by stator poles. In the following analysis, electromagnetic and cogging torque characteristics of inner and outer rotor machines were compared to check if there are other advantages to the external configuration.

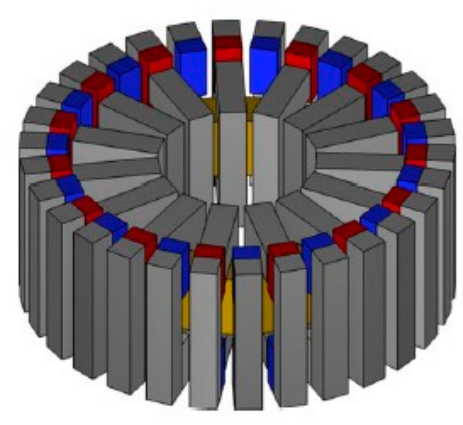

(a)

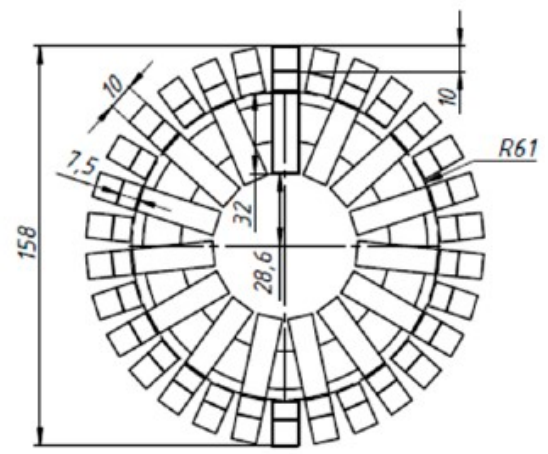

(b)

Figure 6. Single-phase TFM with an outer rotor: (a) 3D FEM model and (b) basic dimensions.

To decrease cogging torque of the machine with an external rotor, the configuration of the machine was changed, and its air-gap radius varied. To see the difference in results between the new model with an external rotor, and the original model with an internal rotor, these machines are analyzed together in 3D FEM.

In the investigated single-phase TFM with an outer rotor, the number, mass and dimensions of the PMs, as well U-shaped stator magnetic poles are the same as in the TFM with an inner rotor. The analysis of the models studied in Section 3 was carried out under the following conditions: the magnetic core of the rotor-steel 1008 (considering the nonlinearity of the magnetization curve of steel); stator magnetic circuit-steel 1008; type of magnets-N42.

Similarly, to the numerical study of the model with an internal rotor, the machine with an external rotor was analyzed by reducing its geometry to a sector equal to $1 / 15$ of the entire model. The sector of the calculation model and its field pattern for the case when there is no current in the winding are shown in Figure 7. 


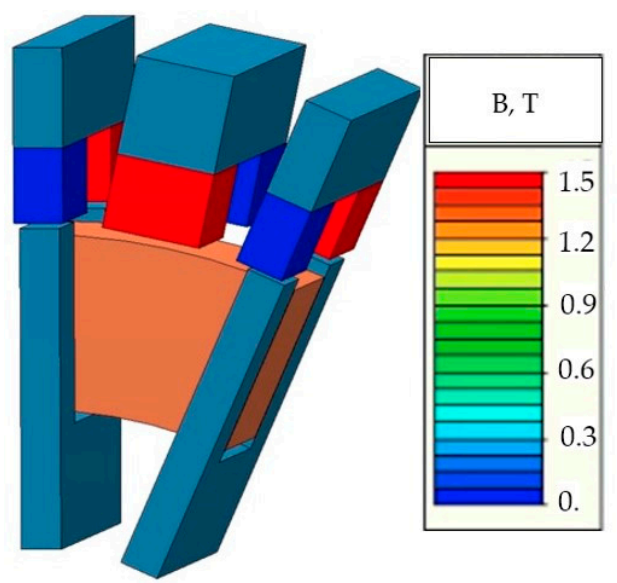

(a)

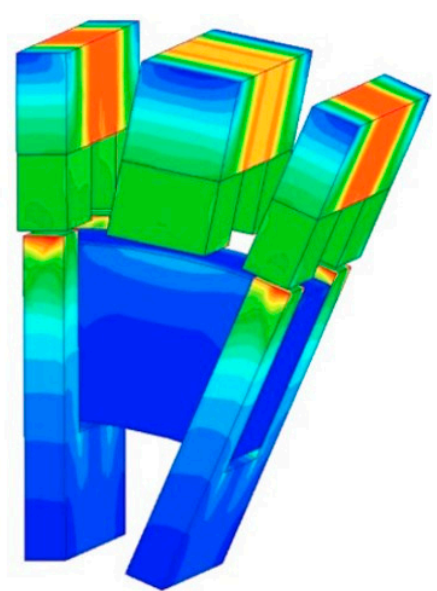

(b)

Figure 7. Computer model of the TFM segment under no current: (a) 3D FEM model of the segment and (b) magnetic flux density distribution in the segment.

In order to investigate the influence of the air-gap radius on the cogging torque of the machine, the parametric analysis is carried out for both TFMs: with outer and inner rotors. The parameter in this parametric analysis is a radius to the middle of the air gap $R_{\delta}$. The cogging torque calculations are provided for various values of $R_{\delta}$ in the range of $56-70 \mathrm{~mm}$. Figure $6 \mathrm{~b}$ ) shows the model where this parameter is $R_{\delta}=61 \mathrm{~mm}$. For various values of $R_{\delta}$, the cogging torque vs. rotor position is calculated for both models, and the results are compared in Figure $8 \mathrm{a}, \mathrm{b}$. Figure $8 \mathrm{c}, \mathrm{d}$ shows the dependence of the electromagnetic torque on the angle of rotor rotation for a model with an external and an internal rotor at a current density in the winding $J=5 \mathrm{~A} / \mathrm{mm}^{2}$.

Upon analyzing these dependences, it should be noted that for both outer and inner rotor TFMs, the same tendency is observed: when the radius $R_{\delta}$ increases, the cogging torque decreases. However, further increase in $R_{\delta}$ leads to an increase in the cogging torque. The values of cogging torque at various air-gap radius for the TFMs with an outer and inner rotor are enclosed in Table 2.

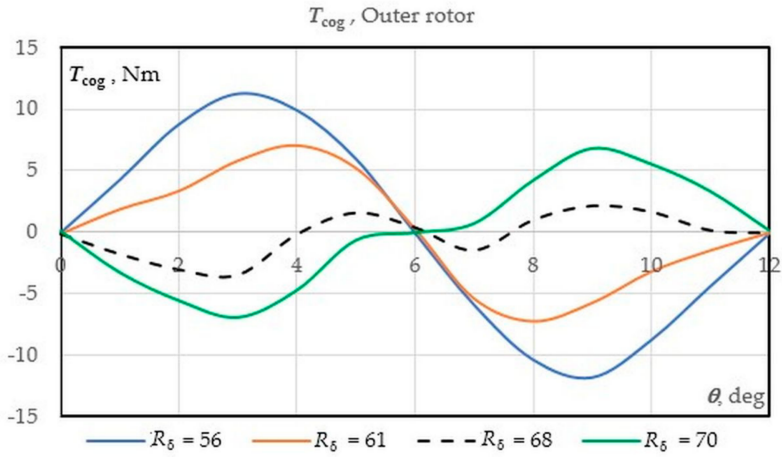

(a)

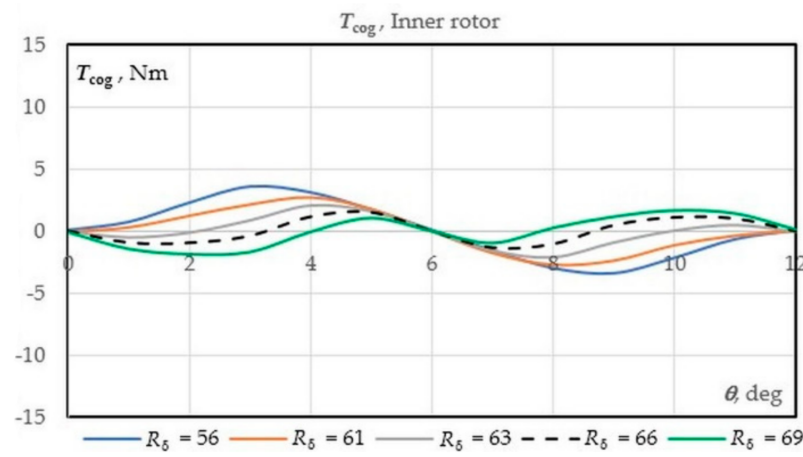

(b)

Figure 8. Cont. 


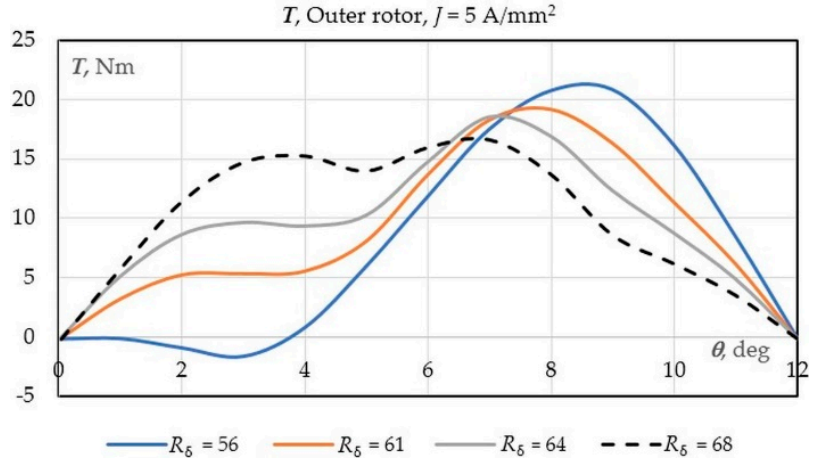

(c)

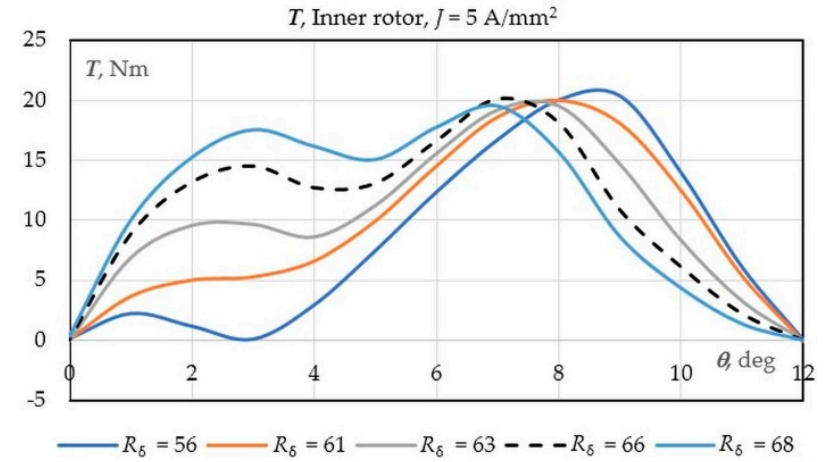

(d)

Figure 8. The torque characteristics of the single-phase TFMs with outer and inner rotors at various air-gap radius $R_{\delta}$ : (a) cogging torque TFM with an outer rotor; (b) cogging torque TFM with an inner rotor; (c) electromagnetic torque with an outer rotor vs. rotor mechanical angle $J=5 \mathrm{~A} / \mathrm{mm}^{2}$; and (d) electromagnetic torque with an inner rotor vs. rotor mechanical angle.

Table 2. Cogging torque values of the TFM with an outer and inner rotor at various air-gap radii.

\begin{tabular}{cccccc}
\hline \multicolumn{7}{c}{ Outer Rotor } \\
\hline Parameter & $R_{\delta}=56$ & $R_{\delta}=61$ & $R_{\delta}=64$ & $R_{\delta}=68$ & $R_{\delta}=70$ \\
\hline$T_{\operatorname{cog}(\max )}, \mathbf{N m}$ & 11.3 & 7.0 & 4.4 & 2.1 & 6.83 \\
\hline Parameter & $R_{\delta}=56$ & $R_{\delta}=61$ & $R_{\delta}=63$ & $R_{\delta}=66$ & $R_{\delta}=69$ \\
\hline$T_{\operatorname{cog}(\max )}, \mathbf{N m}$ & 3.5 & 2.6 & 2.1 & 1.5 & 1.9 \\
\hline
\end{tabular}

The data shown in Table 2 can be graphically expressed in Figure 9 to observe the dependence of the cogging torque on the radius $R_{\delta}$ in both models. The minimum value of cogging torque for the model with an outer rotor happens at $R_{\delta}=68 \mathrm{~mm}$, and for the model with an outer rotor it is at $R_{\delta}=66 \mathrm{~mm}$.

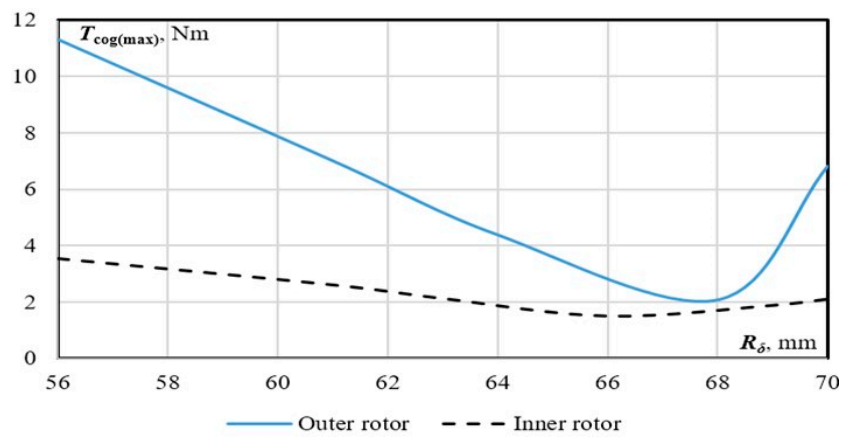

Figure 9. Dependence of the maximum cogging torque on the air-gap radius $R_{\delta}$ in single-phase TFM with an outer and inner rotor.

Thus, the optimal air-gap radius for both models is found. At this air-gap radius, the cogging torque is significantly reduced in comparison to the original version.

\subsection{Varying Coil Dimensions for Improving the Machine's Characteristics}

At the next stage of this study, outer and inner TFM models with the air-gap radius $R_{\delta}$, at which the lowest value of cogging torque is reached, are investigated. In this study, the influence of the winding (coil) dimensions on the stiffness of the external characteristics (terminal voltage) was determined. When examining TFMs with both an inner and an 
outer rotor, the height of the winding was varied. The winding parameters of the outer and inner rotor TFMs are enclosed in Table 3. This table shows the winding configuration of for three values of their height: $b=20,10,4 \mathrm{~mm}$. For example, the slot section for $b=20 \mathrm{~mm}$ and $\mathrm{b}=4 \mathrm{~mm}$, differ by a factor of $5(520 / 104=5)$. Having the same number of turns, $(\mathrm{W}=220)$ and the same filling factor $(\mathrm{k}=0.5)$ the rated current of these windings also differs by $5(5.91 / 1.18=5)$.

Table 3. Winding parameters of the TFM with an outer and inner rotor.

\begin{tabular}{cccc}
\hline Parameter & $\boldsymbol{b}=\mathbf{2 0}$ & $\boldsymbol{b}=\mathbf{1 0}$ & $\boldsymbol{b}=\mathbf{4}$ \\
\hline Height of the coil- $b, \mathrm{~mm}$ & 20 & 10 & 4 \\
Width of the coil- $h, \mathrm{~mm}$ & 26 & 26 & 26 \\
Filling coefficient- $k$ & 0.5 & 0.5 & 0.5 \\
Coil cross-section- $S_{\text {coil }}, \mathrm{mm}^{2}$ & 520 & 260 & 104 \\
Cooper cross-section- $S_{\text {cu, }}, \mathrm{mm}^{2}$ & 260 & 130 & 52 \\
Current density- $J_{\mathrm{n}}, \mathrm{A} / \mathrm{mm}^{2}$ & 5 & 5 & 5 \\
Number of turns, $N$ & 220 & 220 & 220 \\
Conductor cross-section- $S_{\text {wire }}, \mathrm{mm}^{2}$ & 1.18 & 0.59 & 0.24 \\
Rated current $I_{\mathrm{n}}, \mathrm{A}$ & 5.91 & 2.95 & 1.18 \\
\hline
\end{tabular}

The 3D FEM models of the single-phase TFM with an outer and inner rotor with various coil heights are shown in Figure 10a,b. In the first row, the cross-section of the coils is $S_{\text {coil }}=b \times h=20 \times 26=520 \mathrm{~mm}^{2}$. These are the dimensions of the winding of the original model, previously shown in Figures 1 and 6 . The physical model of the original coil used in the TFM prototype (Figure $3 b$ ) is shown in Figure 11. The second row contains the models with the cross-section two times smaller than the original one: $S_{\text {coil }}=b \times h=10$ $\times 26=260 \mathrm{~mm}^{2}$. And, finally, the third row contains models in which the cross-section of the coil is five times smaller than that of the original model: $S_{\text {coil }}=b \times h=4 \times 26=$ $104 \mathrm{~mm}^{2}$.
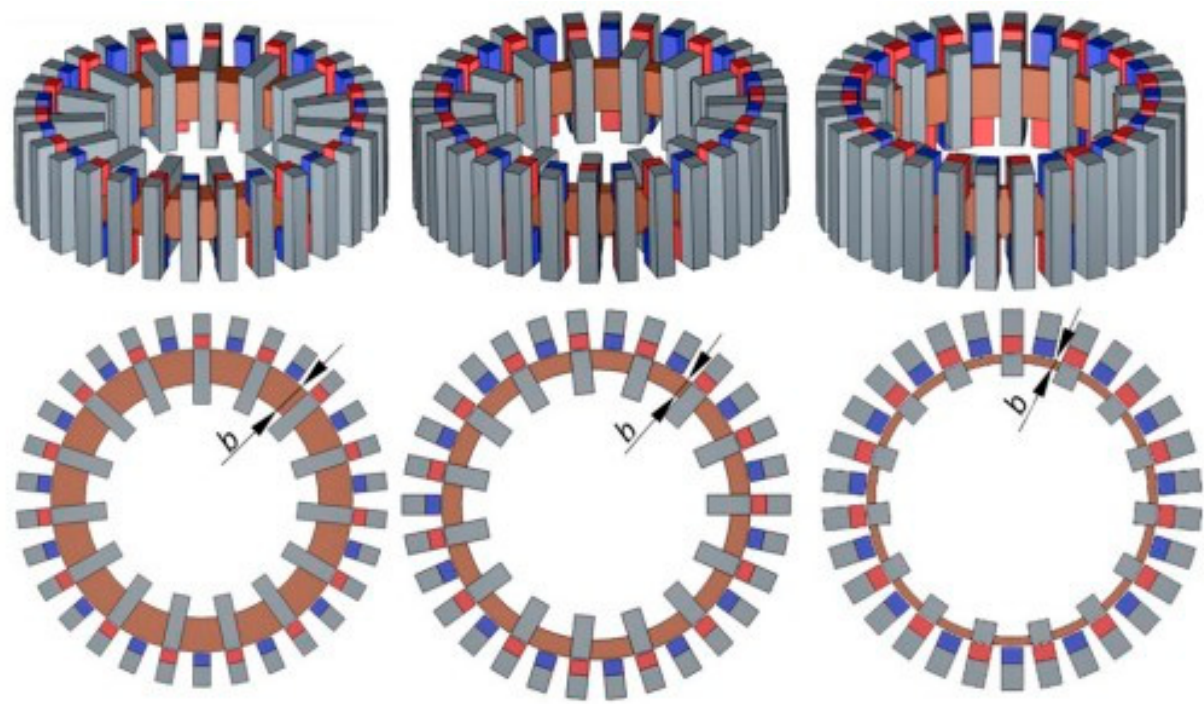

(a)

Figure 10. Cont. 


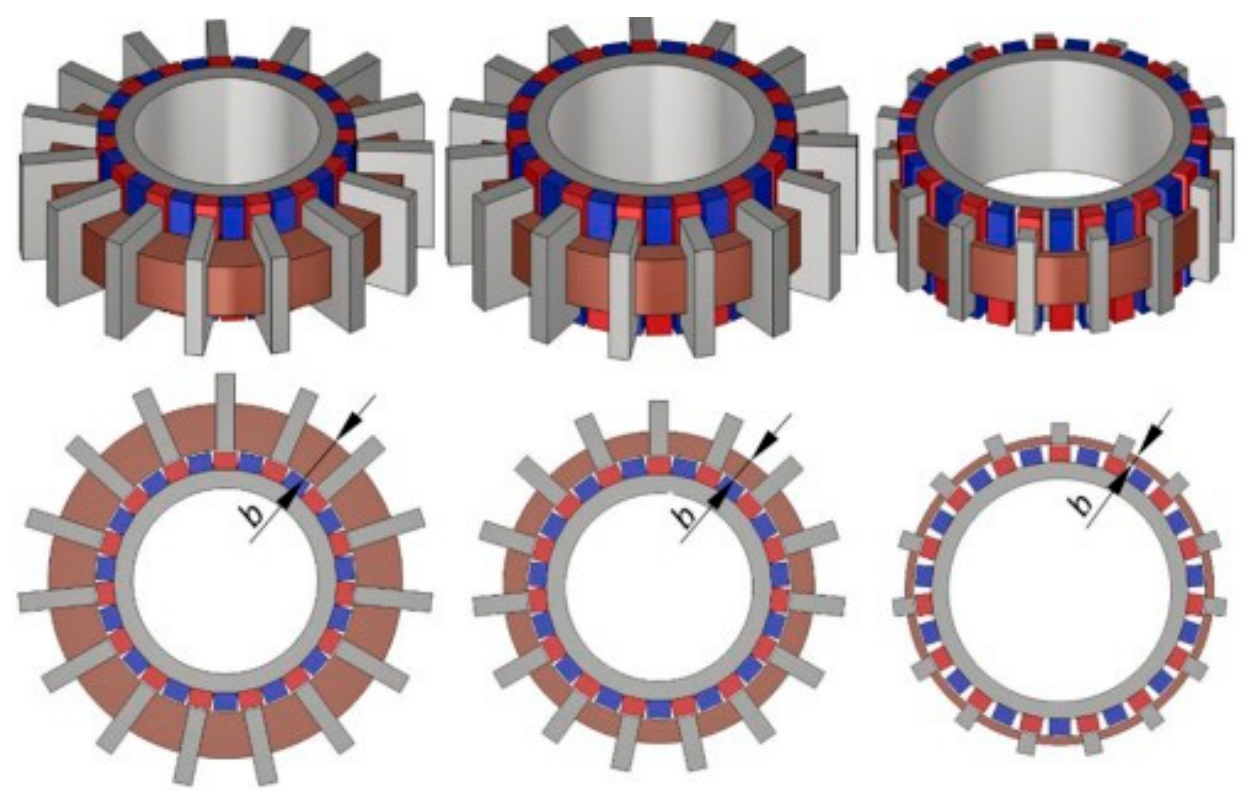

(b)

Figure 10. 3D FEM models of the outer and inner rotor TFMs with various coil height parameters: (a) TFM with an outer rotor and (b) TFM with an inner rotor.

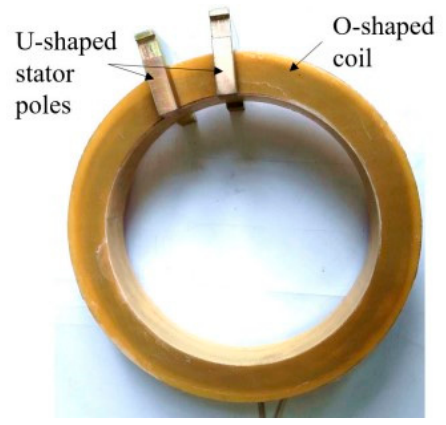

Figure 11. Physical model of the O-shaped phase coil with a height of $20 \mathrm{~mm}$.

The induced voltage characteristics of each of the models are calculated as follows. Variable resistive load is connected to the winding of the machine at the machine's speed of $600 \mathrm{rpm}$. Varying the load resistance, the current density in the coil is changed. Consequently, the voltage at the load terminals is changed too. The rigidity of the terminal voltage is determined from the expression:

$$
\Delta U_{\mathrm{n}}=\frac{U_{0}-U_{\mathrm{n}}}{U_{\mathrm{n}}} \cdot 100 \%,
$$

where $U_{0}$ is the no-load voltage and $U_{\mathrm{n}}$ is the terminal voltage. For a generator with independent excitation, the normal stiffness is usually in the range of $5-10 \%$. The terminal voltage characteristics at various current densities are plotted in Figure 12a,b. In the case of the outer rotor TFM (Figure 12a) at $b=20 \mathrm{~mm}$, the voltage decreases sharply and at $J=2.7 \mathrm{~A} / \mathrm{mm}^{2}$ and takes a zero value, even before reaching the rated current. At $b=10 \mathrm{~mm}$, the voltage also has a sharply falling curve and at $J=6 \mathrm{~A} / \mathrm{mm}^{2}$ it has a zero value. Only at $b=4 \mathrm{~mm}$, the slope of the characteristic is shallow and has an acceptable character. The characteristics of the inner rotor TFM have even higher steepness that those of the TFM with an outer rotor (Figure 12b). For $b=10$ and $20 \mathrm{~mm}$, the terminal voltage drops to zero before even reaching the current density $J=3.5 \mathrm{~A} / \mathrm{mm}^{2}$. At $b=4 \mathrm{~mm}$, the characteristics, as it is in the TFM with an outer rotor, are acceptable. 


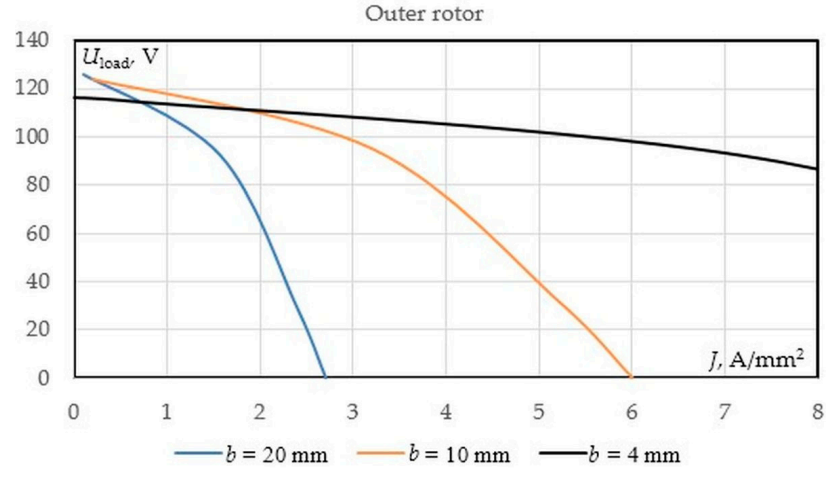

(a)

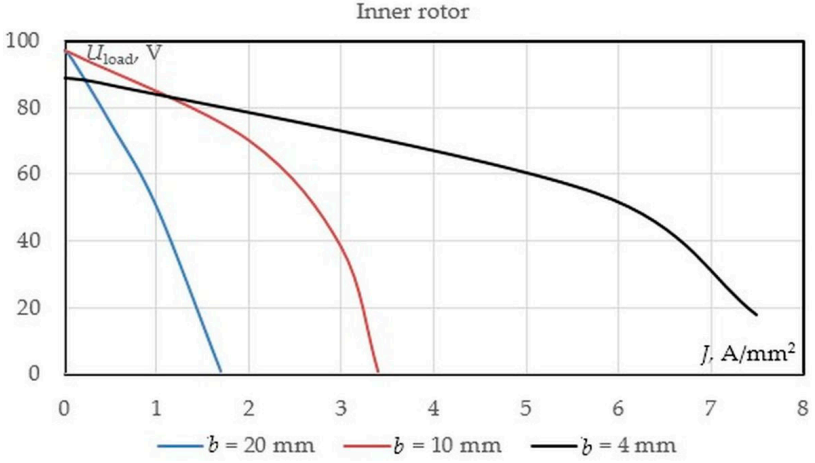

(b)

Figure 12. Terminal voltage characteristics of the outer and inner rotor TFM models with different coil heights: (a) TFM with an outer rotor and (b) TFM with an inner rotor.

The above characteristics show that to ensure an acceptable generator performance at a rated current, it is necessary to reduce the cross section of the generator winding. Therefore, increasing the cross-section of the coil in TFMs does not always mean increasing of its output power. This is explained as follows: a winding with a large cross-section has a magneto-motive force comparable to that of the PMs. Consequently, an increase in the cross-section of the machine winding is possible to a limited value, after which the TFM characteristics significantly deteriorate.

\subsection{Comparison of the Dynamic Characteristics of the Three-Phase TFM with an External and an Internal Rotor}

At this stage, calculations of two different three-phase configurations of the TFM were carried out. Since the best external characteristics were obtained for a configuration with the winding height $b=4 \mathrm{~mm}$, this machine was chosen for further research. For the first configuration of the three-phase TFM, the dimensions of the magnetic system of a single-phase module with an internal rotor were used. The general view of this machine is shown in Figure 10a on the right. The second configuration is the three-phase TFM with an external rotor, shown in Figure $10 \mathrm{~b}$ on the right.

To obtain a three-phase system, the phase B rotor must be displaced relative to phase A by an angle $\alpha=8^{\circ}$ (geometric degrees) and, accordingly, the rotor of phase C-by an angle $\alpha=8^{\circ}$ relative to phase B. General views of the magnetic circuit of the three-phase TFMs with an internal and an external rotor are shown in Figure 13a,b.

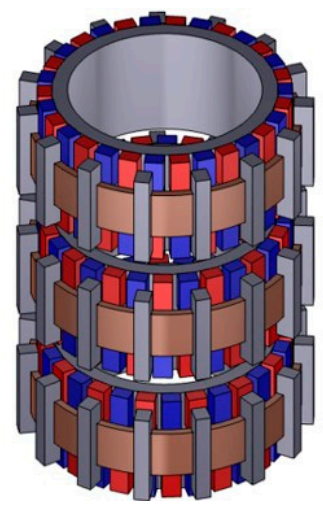

(a)

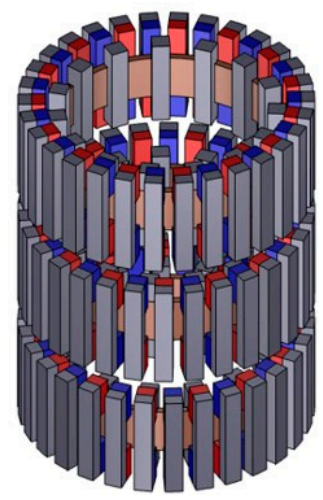

(b)

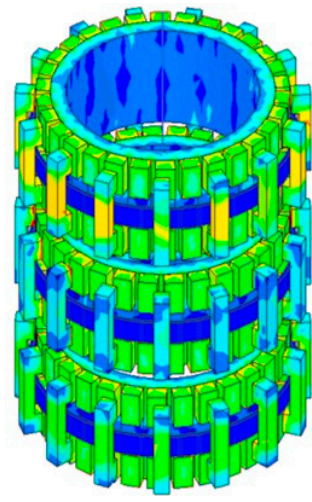

(c)

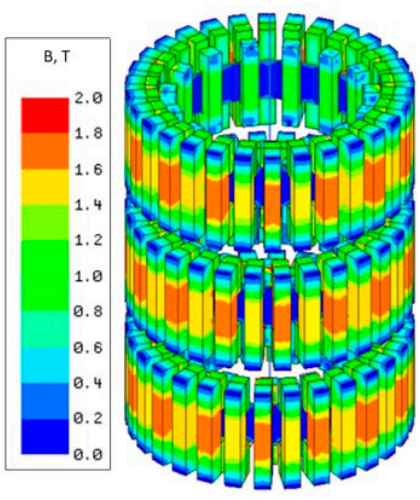

(d)

Figure 13. General view of the magnetic circuit of a three-phase TFMs: (a) with an internal rotor; (b) with an outer rotor. (c) Distribution of the flux density in the machines with an inner rotor and (d) an outer rotor. 
The initial data for calculations (properties of magnets and steel) are the same as for the calculation of single-phase modules. The distribution of the magnetic field for the three-phase TFMs with an inner and an outer rotor is shown in Figure 13c,d.

When calculating the dynamic characteristics of the investigated models, TFM windings were connected to the star and then connected to a rectifier diode bridge, which in turn was connected to the active load $R_{\text {load }}$.

The characteristics of the voltage in the load $U_{\text {load }}$ and the power in the load $P_{\text {load }}$ of three-phase models with an internal and an external rotor for different values of current density are shown in Figure 14. The terminal voltage and output power of the machine with an external rotor is higher than those of the machine with an internal rotor.

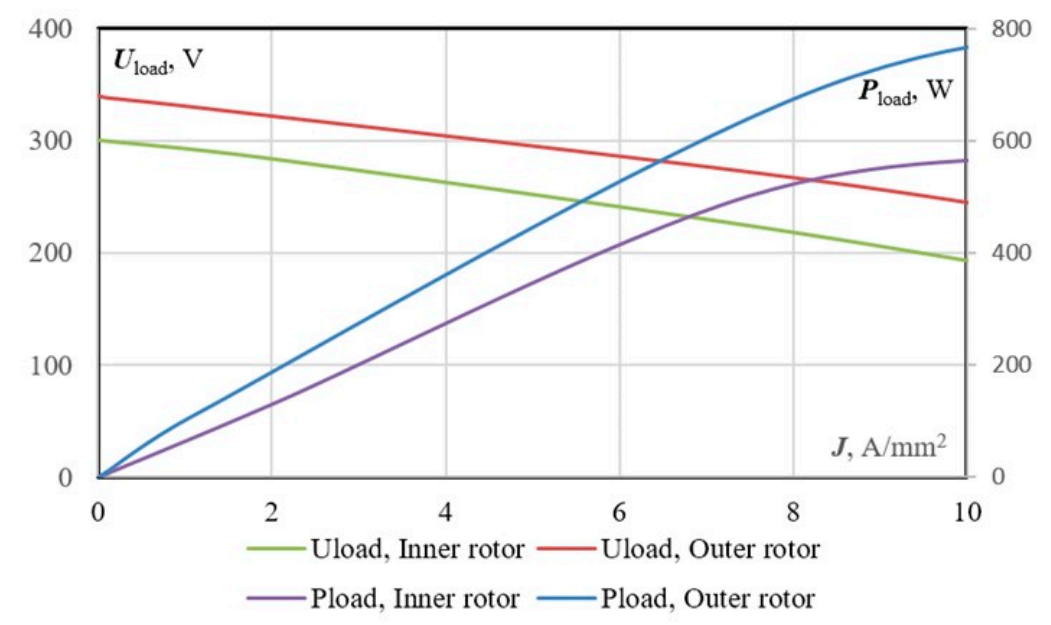

Figure 14. Terminal voltage and output power characteristics of the three-phase 3D FEM TFM models with outer and inner rotors.

The above characteristics demonstrate that the optimal configuration of the studied TFM is the configuration with an outer rotor, coil height of $4 \mathrm{~mm}$, and the air-gap radius of $68 \mathrm{~mm}$.

The key parameters of the three-phase TFMs with an inner rotor and an outer rotor are enclosed in Table 4.

Table 4. Basic parameters of three-phase electric machines with an inner rotor and an outer rotor.

\begin{tabular}{ccc}
\hline Parameter & Inner Rotor & Outer Rotor \\
\hline Number of stator poles, $N$ & 15 & 15 \\
Number of rotor poles, $p$ & 30 & 30 \\
External diameter of the magnetic & 153 & 165 \\
system, MM & 210 & 210 \\
Magnetic system height, $\mathrm{MM}$ & 7.7 & 9.1 \\
Total mass of active parts, $\mathrm{m}_{\mathrm{a}}, \mathrm{Kr}$ & 0.8 & 0.8 \\
Working gap, $\mathrm{MM}$ & $\mathrm{N} 42$ & $\mathrm{~N} 42$ \\
Permanent magnet type & 600 & 600 \\
Rated speed, $\mathrm{n}, \mathrm{rpm}$ & 0.38 & 0.45 \\
Rated power, $P_{\mathrm{n}}, \mathrm{kW}$ & 0.05 & 0.05 \\
\hline Specific power, $P_{\mathrm{e}}=P_{\mathrm{n}} / \mathrm{m}_{\mathrm{a}}$ &
\end{tabular}

\section{Discussion}

As a result of numerical studies, it was found that in order to ensure the maximum specific characteristics of the TFM at rated current, the cross-section of the winding wire must be properly evaluated. The magnetomotive force (MMF) of the winding needs to be matched with the magnetomotive force of permanent magnets. Increasing the winding cross-section will not always improve the characteristics of the machine, and, in some cases, 
can even lead to the significant drawbacks in performance. This is explained as follows, a winding with a large cross-section has an MMF comparable to the MMF of permanent magnets, i.e., an increase in the cross-section of the machine winding is possible to a limited value, after which the TFM characteristics significantly deteriorate. Only for a certain range of winding cross-section the maximum power at the rated current ensured. Therefore, this circumstance should be considered when designing and developing TFM machines.

\section{Conclusions}

The reliability of the numerical model is confirmed by its comparison to an experimental model. The discrepancy between the calculated and experimental values does not exceed $10 \%$-for the electromagnetic torque, and $5 \%$-for the induced voltage. This testifies to the adequacy of the computer model.

The validated computer model of the TFM was then used in the parametric studies which investigated the influence of the machine's geometry on its electromechanical characteristics. As a result, it has been observed that the air-gap radius has a significant influence on the TFMs' cogging torque. By varying the air-gap radius of the machine within $14 \mathrm{~mm}$, the optimal air-gap radius of the TFM was found. With this air-gap radius, the cogging torque of the model with an inner rotor was reduced by 2.3 times, and the cogging torque of the model with an outer rotor was reduced by 5.4 times. In addition, the research investigated the influence of winding geometry on the characteristics of the machines. Varying the height of the coil, it was observed that in order to achieve the maximum output power of the machine, the cross-section of the winding must be matched to the magneto-motive force of permanent magnets. As a result of numerical studies, the range of the winding cross-section was determined, at which a higher value of output power at rated current is achieved.

Author Contributions: Conceptualization, O.D. and G.V.; methodology, review, editing and research grant holder, R.G.; software and conceptualization, G.R. All authors have read and agreed to the published version of the manuscript.

Funding: This research is based on research/work supported in part by Eskom (grant number: 26892278). The research findings are those of the authors and not of Eskom.

Institutional Review Board Statement: Not applicable.

Informed Consent Statement: Not applicable.

Data Availability Statement: Data can be found at: http://toc.proceedings.com/37116webtoc.pdf.

Conflicts of Interest: The authors declare no conflict of interest.

\section{References}

1. Liu, C.; Zhu, J.; Wang, Y.; Lei, G.; Guo, Y. Design Considerations of PM Transverse Flux Machines With Soft Magnetic Composite Cores. IEEE Trans. Appl. Supercond. 2016, 26, 1-5. [CrossRef]

2. Dobzhanskyi, O.; Gouws, R.; Amiri, E. Comparison analysis of PM transverse flux outer rotor machines with and without magnetic shunts. In Proceedings of the 2016 IEEE Energy Conversion Congress and Exposition (ECCE), Milwaukee, WI, USA, 18-22 September 2016; pp. 1-8.

3. Ahmed, A.; Husain, I. Power factor improvement of a transverse flux machine with high torque density. In Proceedings of the 2017 IEEE International Electric Machines and Drives Conference (IEMDC), Miami, FL, USA, 21-24 May 2017; pp. 1-6.

4. Bao, G.Q.; Wang, J.K.; Zhang, D.; Jiang, J.Z. An Investigation of Multi-phase Transverse Flux Permanent Magnet Machine. In Proceedings of the 2006 CES/IEEE 5th International Power Electronics and Motion Control Conference, Shanghai, China, 14-16 August 2006; pp. 1-4.

5. Golatgaonkar, P.; Chaudhari, B.; Ugale, R. Torque ripple reduction in homopolar poly-phase transverse flux machine. J. Eng. 2019, 2019, 3553-3558. [CrossRef]

6. Hodge, C.; Mattick, D. The electric warship VI. A Paper for the Institute of Marine Engineers (IMarE), 12 December 2000.

7. Dobzhanskyi, O.; Gouws, R. Magnetic Circuit Analysis of the Low Cost in Wheel Switching Flux Motor for HEV Applications. In Proceedings of the 2019 IEEE International Electric Machines \& Drives Conference (IEMDC), San Diego, CA, USA, 12-15 May 2019. 
8. Dobzhanskyi, O.; Gouws, R.; Amiri, E. Optimal Switching-Flux Motor Design and its Cogging Effect Reduction. In Proceedings of the 2017 IEEE 58th International Scientific Conference on Power and Electrical Engineering of Riga Technical University (RTUCON), Riga, Latvia, 12-13 October 2017.

9. Dobzhanskyi, O.; Gouws, R.; Amiri, E. On the role of magnetic shunts on increasing performance of transverse-flux machines. IEEE Trans. Magn. 2016, 53, 1-9. [CrossRef]

10. Rahman, K.M.; Patel, N.R.; Ward, T.G.; Nagashima, J.M.; Caricchi, F.; Crescimbini, F. Application of direct-drive wheel motor for fuel cell electric and hybrid electric vehicle propulsion system. IEEE Trans. Ind. Appl. 2006, 42, 1185-1192. [CrossRef]

11. Chang, J.; Kang, D.; Lee, J.; Hong, J. Development of transverse flux linear motor with permanent-magnet excitation for direct-drive applications. IEEE Trans. Magn. 2005, 41, 1936-1939. [CrossRef]

12. Kang, D.H.; Chun, Y.H.; Weh, H. Analysis and optimal design of transverse flux linear motor with PM excitation for railway traction. IEEE Proc. Electr. Power Appl. 2003, 150, 493-499. [CrossRef]

13. Caricchi, F.; Crescimbini, F.; Honorati, O. Modular axial-flux permanent-magnet motor for ship propulsion drives. IEEE Trans. Energy Convers. 1999, 14, 673-679. [CrossRef]

14. Dobzhanskyi, O.; Gouws, R.; Amiri, E. Performance analysis of the TF machine with double coil. In Proceedings of the IEEE 58th International Scientific Conference on Power and Electrical Engineering of Riga Technical University (RTUCON), Riga, Latvia, 12-13 October 2017.

15. Dobzhanskyi, O. Study on Transverse-Flux Machine. Ph.D. Thesis, Louisiana State University, Baton Rouge, LA, USA, 2009.

16. Patterson, G.; Koseki, T.; Aoyama, Y.; Sako, K. Simple modeling and prototype experiments for a new high-thrust low-speed permanent-magnet disk rotor. IEEE Trans. Ind. Appl. 2011, 47, 65-71. [CrossRef]

17. Chabchoub, M.; Salah, I.; Krebs, G.; Neji, R.; Marchand, C. PMSM cogging torque reduction: Comparison between different shapes of magnet. In Proceedings of the 2012 First International Conference on Renewable Energies and Vehicular Technology (REVET), Hammamet, Tunisia, 26-28 March 2012. 